only this - is true?

Scientific realists argue that mature and genuinely successful scientific theories should be accepted as nearly true. The main defence of this optimistic attitude is known as 'the no miracle argument' because it is based on Hilary Putnam's slogan that "scientific realism is the only philosophy of science that doesn't make the success of science a miracle".

Modern defenders of scientific realism, most notably the philosopher Richard Boyd at Cornell University, have based their defence on the idea that the impressive predictive and explanatory successes of scientific theories would remain unaccounted for unless we accept that the entities, processes and causal mechanisms they posit to operate behind the phenomena are real. They dismiss instrumentalist accounts of scientific theories by pointing out that they leave the success of science unexplained. If theories are merely 'black boxes', the only virtue of which is that they offer the most economical classification of the observable phenomena, then there is no

\section{At a glance}

\section{Sex, Color, and Mate Choice in Guppies}

by Anne E. Houde

Princeton University Press: 1997. Pp. 210. \$49.50,

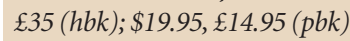

It is hard not to like a book with an appendix titled "How to build a better bordello", although the subjects on display here are male guppies. Building an effective bordello, or at least a reliable way to determine mating preferences, is important to biologists who study guppies, and, like much of the rest of this book, turns out to be of interest to researchers into sexual selection in other species as well.

For studies of adaptation in the wild in general and of mate choice in particular, guppies have been a model system for many years, and the author synthesizes the results of decades of research. She carefully distinguishes between speculation and fact, and provides one of the most lucid analyses of current mate-choice models I have read. Literature cited on sexual selection is impressively broad for vertebrates, less so for insects and other invertebrates.

Is the book just for 'guppy people'? Yes and no; researchers anxious to keep up with the nuances of the latest experiments on the significance of the amount of orange area relative to the intensity of orange will find details of limited interest to the rest of us. The last few chapters, however, particularly the concluding section, provide an inspiring guide to future directions in behavioural ecology.

Marlene Zuk Department of Biology, University of California, Riverside, California 92521, USA.

reason to expect that they can be, as the French philosopher and scientist Pierre Duhem put it, "prophets for us". To counter that these black boxes are empirically adequate - that they save all phenomena - would not be much of an improvement on the instrumentalist position. For what needs explanation is precisely the fact, if it is a fact, that scientific theories save the phenomena. To say that they do is merely to assert what needs to be explained.

The realist explanation of the success of science does not go unchallenged. One line of criticism is that it is too easy to obtain empirical success: just 'write into' the theory the right observational consequences. Then the theory would not fail to predict them. But realists are quick to regiment their argument. There is a kind of prediction that can support only a realist understanding of the theory that entails it: the prediction of novel phenomena. For there is no explanation of why the theory predicts the existence of a novel phenomenon, other than to say that the phenomenon is brought about by

\section{The Handicap Principle: A Missing Piece of Darwin's Puzzle}

by Amotz Zahavi and Avishag Zahavi

Oxford University Press: 1997. Pp. 286. \$30, £18.99

At first sight, the peacocks tail emblazoned across the dustjacket is an affront to evolution by natural selection. Surely such a cumbersome trait could not arise by 'survival of the fittest'? Such naive criticisms were pre-empted by Darwin with his theory of sexual selection.

In the mid-1970s, Amotz Zahavi published a controversial series of papers in which he claimed that all previous theories of sexual selection were flawed. Instead, he proposed his handicap principle. Moreover, he asserted that Darwin's demarcation between natural and sexual selection was incorrect, the true distinction being between natural and 'signal' selection.

This insightful yet accessible book explains the handicap principle and applies it to the analysis of a wide variety of behavioural phenomena: altruism, mate choice, the signalling between predator and prey, to name but a few. Many of the Zahavis' ideas are inspired and should be required reading for all zoologists and interested lay people. Unfortunately, this high praise must come with at least one caveat: the book is extremely tendentious. Although the authors provide a rigorous defence of their own position, rival theories are often unfairly dismissed with glib and specious arguments.

Overall, this is a beguiling tale, pleasantly illustrated, which is of genuine and general importance to our understanding of evolution and animal behaviour.

Steven Siller British Telecommunications Laboratories, Martlesham Heath IP5 3RE, UK. the theoretical mechanisms posited by the theory. A novel prediction is typically taken to be the prediction of a phenomenon whose existence is ascertained only after a theory suggests its existence.

But this cannot be the whole story because theories also receive support from explaining phenomena that are already known. So some philosophers argue that the 'temporal view' of novelty is inadequate and should be replaced by a 'novelty in use' view: a prediction of an already known phenomenon can be 'use novel' with respect to a theory provided that information about this phenomenon was not used in the construction of the theory. Yet it has been notoriously difficult to make precise the intuitive idea of 'use novelty'.

A Novel Defence of Scientific Realism takes up this challenge and meets it beautifully. Jarrett Leplin analyses 'novelty' by reference to two requirements: independence and uniqueness. The core idea is that a prediction of a phenomenon $\mathrm{O}$, be it already known or hitherto unforeseen, is novel for a theory $\mathrm{T}$ if no information about $\mathrm{O}$ is necessary for the prediction of $\mathrm{O}$ by $\mathrm{T}$ and if there is no other theory available that explains why $\mathrm{O}$ should be expected.

Leplin puts his analysis of novelty to work in his defence of scientific realism. His argument is not new. It is a variant of the known line that a realist understanding of theories that entail novel predictions offers the only explanation of their capacity to yield such predictions. But I think this line is right, and here Leplin does a thorough job in developing the realist position and blocking well-known counter-arguments.

However, the realism he wants to entertain is rather weak. His 'minimal epistemic realism' is committed merely to the claim that "there are possible empirical conditions that would warrant attributing some measure of truth to theories - not merely to their observable consequences, but to theories themselves". As he knows, many realists would aspire to more. They would, for instance, try to defend the more substantive thesis that the distinctive mode of inference involved in the generation and acceptance of explanatory hypotheses in science, known as inference to the best explanation, is conducive to truth. Here Leplin parts company with his fellow realists and wishes them bon voyage. Their voyage has to be successful if the rationality of belief in unobservable entities is to be defended. Consequently, more work needs to done to defend a full-blooded realism. But this book is a splendid starting point.

Stathis Psillos is in the Department of Philosophy, London School of Economics, Houghton Street, London WC2A 2AE, UK. 